\title{
Car body and bogie connection modification for track curves passability improvement
}

\author{
Vladimír Hauser ${ }^{1, *}$, Olena S. Nozhenko ${ }^{1}$, Kateryna O. Kravchenko ${ }^{1}$, Mária Loulová ${ }^{1}$, \\ Juraj Gerlici ${ }^{1}$, Tomáś Lack ${ }^{1}$ \\ ${ }^{1}$ University of Žilina, Faculty of Mechanical Engineering, Department of Transport and Handling \\ Machines, Univerzitná 1, 01026 Žilina, Slovak Republic
}

\begin{abstract}
For Tram cars, it is often necessary to operate in cities on strongly curved track, which is followed by an increased effect of the vehicle on the track. Especially, this increased effect occurs in spiral transition curves situated between direct and arc sections or between two arc sections of different radius. In such case, increased guiding forces, creep in the rail - wheel contact, wear and noise generation can be observed. Exactly with the aim to reduce these undesirable effects we designed a tram bogie with steered wheelsets. This paper deals with a modification of its coupling to vehicle body in order to improve vehicle dynamics in transition curves. Proposed innovative construction of this coupling unit is registered by authors under Utility Model Nr. u201609015 and Utility Model Nr. u201703246. Description of the proposed way for a vehicle to pass through curved track with regard to bogie-body coupling and wheelset steering mechanisms with usage of multibody computing software is given in this paper.
\end{abstract}

Keywords: bogie to vehicle body coupling, track transition curves, tramcar throughput improvement

\section{Introduction}

The way a vehicle passes a track arc depends on many factors. The most important of these include the bogie wheelbase, the distance of pivot pins, the way the car body is mounted on the bogie, the design of the wheelset guiding in the bogie, the track gauge and the width of the track free channel with which the geometry of the wheel and rail profiles is directly related. The most favorable situation for the vehicle during a ride in a curve is the radial position, the wheelset guides should provide zero angles of attack, the wheel and rail profiles should provide one-point contact as well as lateral displacement of the wheel from the track axis such that the change of the radius of the outer and inner wheels would compensate the difference in the lengths of the outer and inner rails. Fulfilling these conditions will result in a reduction in creep velocities in wheel-rail contacts, minimizing vehicle riding resistance in curve, extending wheel and rail profile service life, reducing bogie and track load, and reducing traffic noise. It is particularly desirable to achieve such a favorable condition in an environment with frequent occurrences of small radius arcs, such

\footnotetext{
* Corresponding author: vladimir.hauser@fstroj.uniza.sk

Reviewers: Marek Macko, Milan Žmindák
} 
as the railways of public transport vehicles, where the increased contact wear of the contact pair profiles and, in particular, the increased noise generation is significant problem [1 - 3]. The team of authors deals with the solution of this problem in the form of atypical bogie design ensuring favorable transition through track arcs [4, 5]. A key element of the proposed solution is a mechanism providing radial steering of the wheelsets while riding along a curved section of the track, where the position of wheelsets is derived from the bogie frame rotation relative to the car body.

\section{The wheelset control mechanism}

The purpose of the control mechanism is to define the position of the wheelsets, and it is desirable that due to the operation of the mechanism there is no excitation of the undulatory movement of the vehicle when driving on a straight track. The steering is carried out by moving of the axle boxes in the longitudinal direction by means of a steering mechanism. The input variable is the angle of rotation of the bogie towards the vehicle frame. The output variable is the angle of rotation of the wheelset towards the bogie frame, which is created by moving the axle boxes of the wheelset guiding in an opposite direction. A schematic diagram of the proposed bogie design is shown in Fig. 1a) A cross section diagram of the proposed bogie design is shown in Fig. 1b).

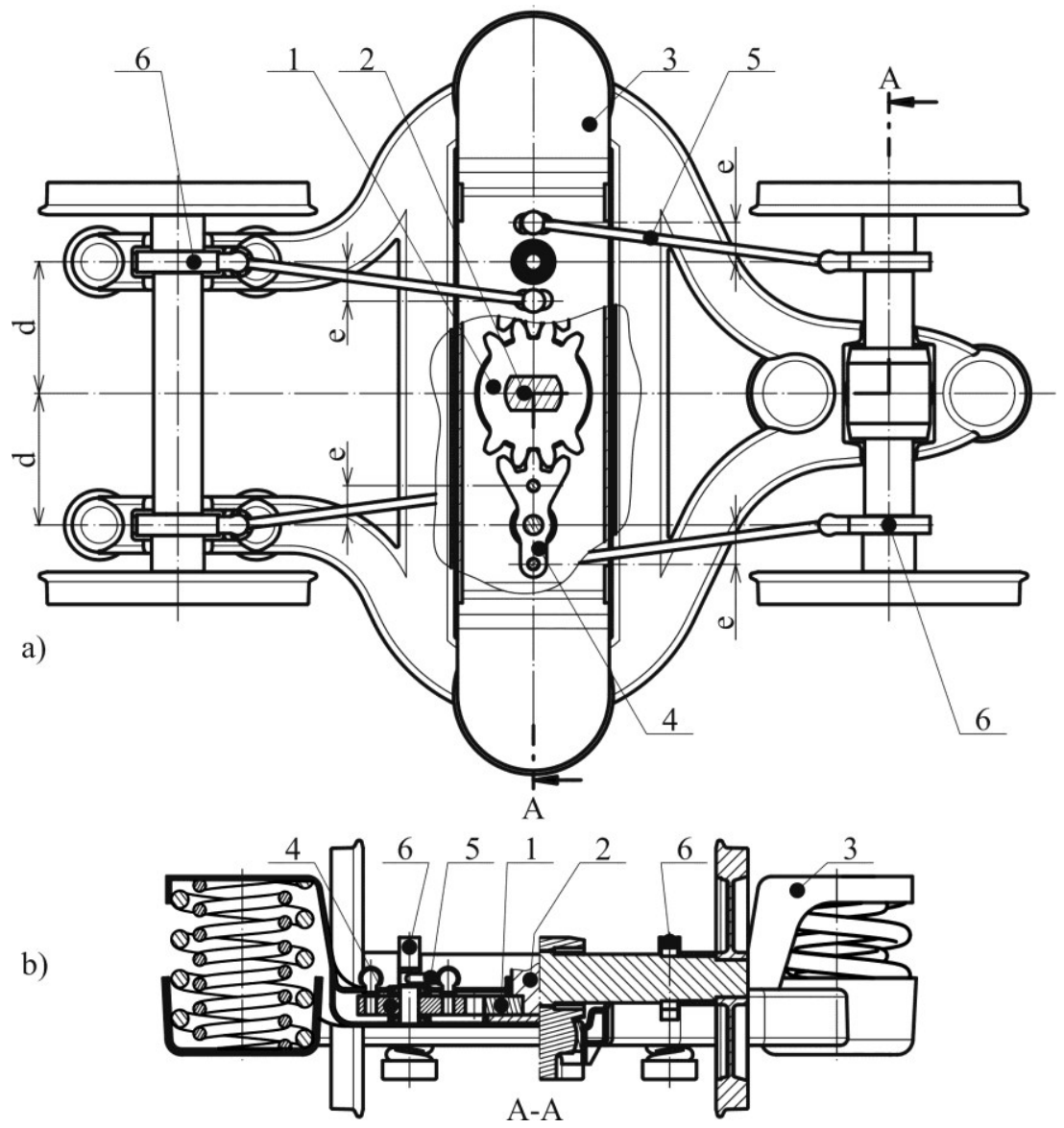

Fig. 1. a) schematic diagram of the proposed bogie design b) cross section diagram of the proposed bogie design 
The design of the wheelset steering mechanism requires a gear wheel segment (1) being mounted on the pivot coupling the car body with the bogie (2). The bogie rotation is realized around the pivot (2). Thus, the gear frame (3) has only one degree of freedom towards the car body. Levers with a gear segment are rotatably mounted on the gear frame (4). The levers (4) are coupled by means of rods (5) to the axle boxes (6). With regard to the suspension operation, spherical joints are considered to attach the rods to the levers. For a correct function of the proposed mechanism, it was necessary to determine the gear ratio between the gear segments as well as the dimensions "e" and "d".

Relationships for the calculation of these dimensions can be determined from the requirement that the vehicle has to pass through a track arc with radially rotated wheelsets, as shown in Fig. 2. The following relationships are based on the assumption that the pivot pin is located at the midpoint of the wheelbase of the bogie, shown in Fig. 2 as the dimension "b".

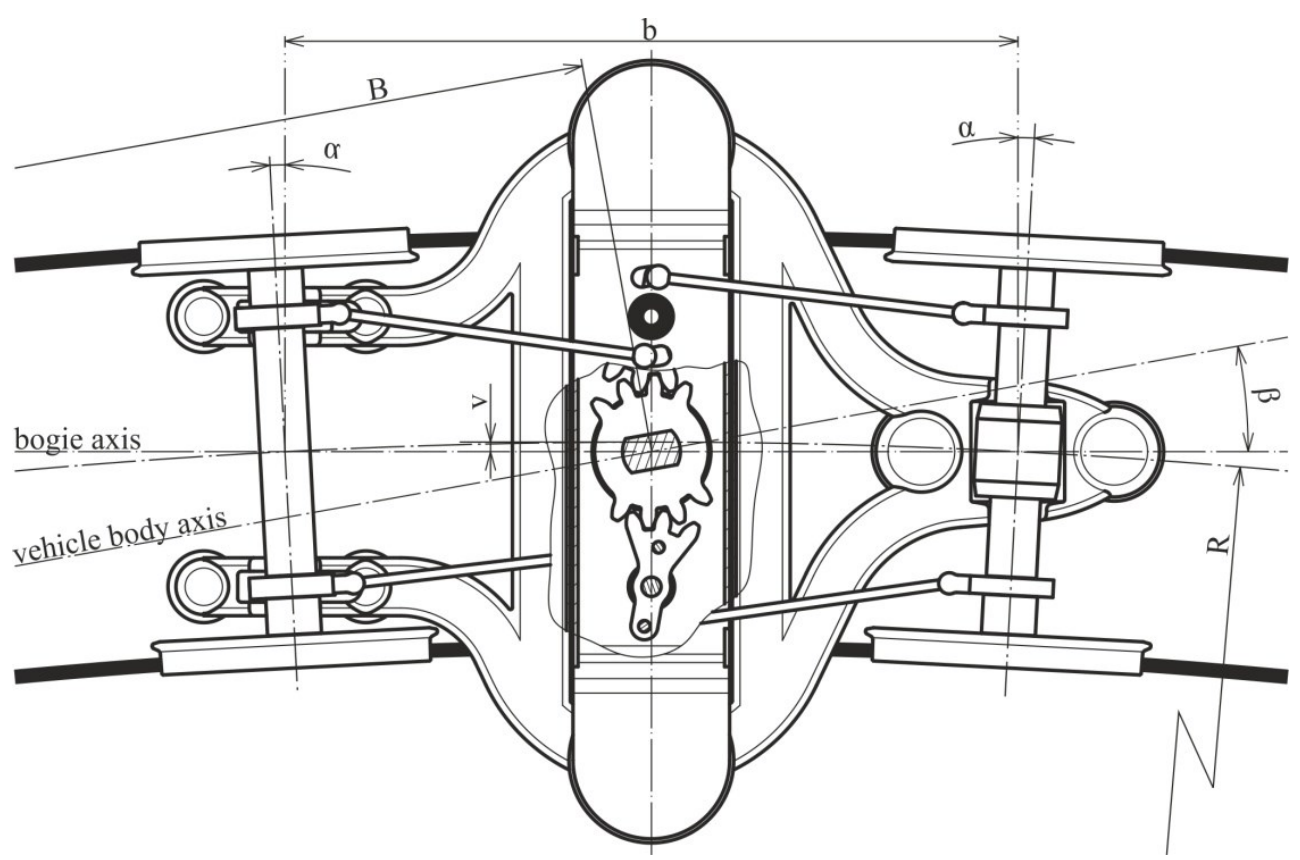

Fig. 2 Expected way of vehicle passing a track arc (ride direction to the right, front bogie shown)

For the angle of rotation of the wheelset towards the bogie frame $\alpha$ [rad] we can write a relationship:

$$
\alpha=\arcsin \frac{b}{2 R}
$$

where variable $b[\mathrm{~mm}]$ represents the bogie wheelbase and $\mathrm{R}[\mathrm{mm}]$ the radius of the track arc. For the angle of rotation of the bogie relative to the car body, it is possible to write the relationship:

$$
\beta=\arcsin \frac{B}{2(R-v)}
$$


Where the variable $B$ [mm] represents the distance of the pivot pins and $\mathrm{v}[\mathrm{mm}]$ represents the lateral deflection of the pivot from the axis of the track in the arc. For the calculation of this value it is possible to use relation (3), or relation (4):

$$
\begin{aligned}
& v=R-\frac{b}{2 \tan \alpha} \\
& v=R-\sqrt{R^{2}-\left(\frac{b}{2}\right)^{2}}
\end{aligned}
$$

The wheelset steering mechanism is required to rotate the wheelsets in the bogie when rotating the bogie frame towards the car body. This is done largely by longitudinally moving the axle boxes in the bogie frame. The value of this longitudinal displacement $x_{d}$ [mm] can be expressed by:

$$
x_{d}=d \cdot \sin \alpha
$$

Where $d[\mathrm{~mm}]$ is the distance of the axle box from the longitudinal axis of the bogie. It is necessary that the lever joints with the gear segment are being moved in the longitudinal direction exactly by the $x_{d}$ value when the bogie is turning. Therefore, for the value of the dimension e [mm], it is possible to write the relationship:

$$
e=\frac{x_{d}}{\sin \beta}
$$

After fitting relations (1), (2) and (5) to (6), the value of dimension e [mm] can be modified to:

$$
e=\frac{d \cdot b}{R} \cdot \frac{R-v}{B}
$$

Since the variable $\mathrm{v}$ reaches values much smaller than the variable $\mathrm{R}$, it can be neglected in the numerator of the second fraction. Consequently, it is possible to write the following relation for dimension e $[\mathrm{mm}]$ :

$$
e=\frac{d \cdot b}{B}
$$

For the considered vehicle with bogie wheelbase $b=1900 \mathrm{~mm}$, the distance between the pivot pins $B=6400 \mathrm{~mm}$ and the joints situated at a distance $\mathrm{d}=350 \mathrm{~mm}$ from the longitudinal axis of the vehicle, the resulting value of $\mathrm{e}=104 \mathrm{~mm}$.

As the bogie design is asymmetrical, several ways of placing the bogie under the vehicle car are considered. It is necessary to find out which position will be more favorable in terms of both ride in track arcs and ride stability. 


\section{Examinated options of bogie mounting on the car body}

There are three specific requirements for attaching the bogie to the car body:

1. Ensure wheelset steering that is derived from the pivot pin with the gear segment shown in Fig. 1 under items (1) and (2).

2. Exit the vehicle from the straight-line arc to bring the vehicle to a centered position with respect to the track axis, while the steering control derived from the pivot pin must not cause the undulatory movement of the vehicle to be excited while riding in a straight track.

3. Decrease the amplitude of the lateral force when riding through the track transition curve.

In order to meet these criteria, two ways of mounting a pivot pin were proposed. The first method considers a pivot pin firmly attached to the bottom of the car body and its rotary mounting on the frame of the bogie gear. Such a solution is fully in line with the relationships mentioned in Chapter 2, in the circular parts of the arc one can expect its correct function. However, it is necessary to check the vehicle's response to ride on the track transition curve when there may be a certain increase in angles of attack, and therefore the downgrade of the vehicle's characteristics must be examined. It is also necessary to pay attention to the undulatory movement of the vehicle after its return onto the straight track.

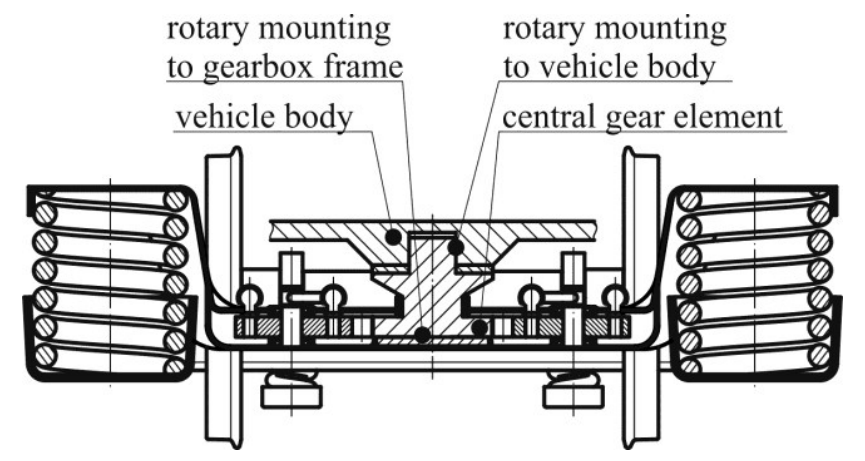

Fig. 3. Bogie with a coupling element placed in a rotary way in two places

The second method (Figure 3) considers a pivot pin attached to the bottom of the car body by means of a flexible element with a damping. At the other end, the pivot pin is also rotary mounted on the bogie gear frame. Such a solution will provide an improvement in the vehicle's properties when riding through a track transition curve when each of the vehicle bogies is in a track arc of another radius. The flexible rotation damping element of the pivot makes it possible to stabilize the vehicle on a straight track. It is necessary to pay attention to the ride through circular arcs, where the rotary mounting of the pivot pin on the bottom of the car body may cause some downgrade in the driving characteristics.

From the bogie design, its asymmetrical composition is evident in relation to the lateral plane going through the pivot pin, resulting in two possibilities of placing the bogies under the car body as shown in Fig. 4 . 

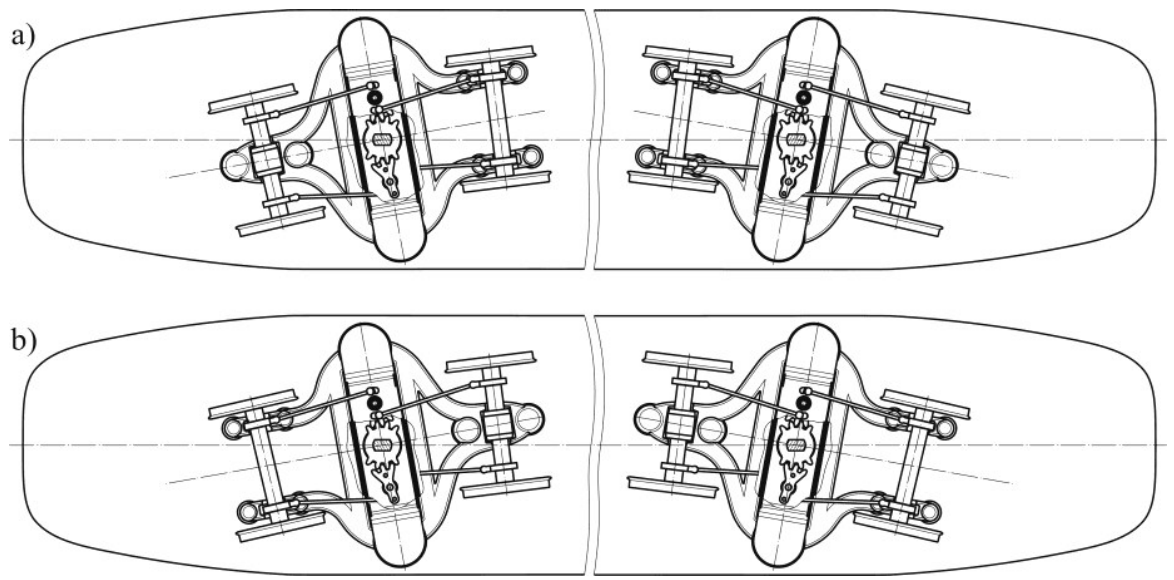

Fig. 4. Position of the bogie under the vehicle body

a) wheelset with a single axle box turned towards the stem

b) wheelset with a single axle box turned towards the vehicle centre

For both the bogie placement as well as for both the above-described pivot pin mount methods, a vehicle ride simulation analysis was performed to determine the suitability of the proposed solutions.

\section{Simulation analysis of vehicle ride}

Vehicle simulation analysis was performed in the Simpack 9.9 program environment using the Rail module. A vehicle model was used, the basic parameters of which are close to the T3 vehicle for the $1000 \mathrm{~mm}$ gauge [6], using the bogie of the described design. Creating the vehicle model itself was described by the authors in detail in [7].

It is generally known that, regarding many parameters, the ride of the vehicle in the opposite direction S-arc is very problematic [8 - 11]. The aim of the authors was to examine the response of the different variants of the location and mounting of the vehicle bogie to such situation [12 - 14]. In the simulation, a ride of the vehicle on a track according to the standard [15], which consists of straight sections, a transition curve of a clothoid shape, and two counter-arcs with a radius of $50 \mathrm{~m}$ was considered. The length of each section of the track and its arrangement is shown in Fig. 5. The straight section at the beginning of the track is used to stabilize the vehicle. The final straight section serves to verify the vehicle's stability against undulatory movement. The driving speed was set constantly at $10 \mathrm{~km} / \mathrm{h}$ without driving and braking forces.

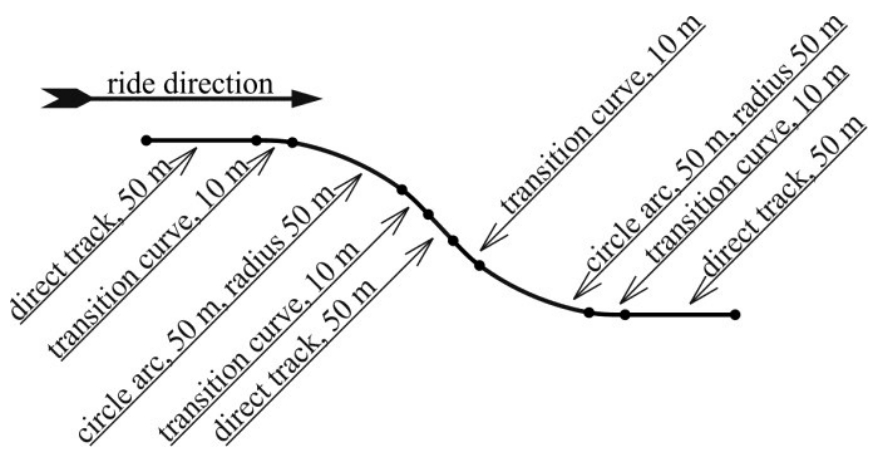

Fig. 5. Track used in simulation 
During the calculation, among other variables were recorded, in particular, the value of the lateral displacement of the wheelset, the angles of attack, the force acting in the wheel rail contact pairs and the wear number. These signals were obtained for each wheel - rail contact pair. Due to the large range of calculated data, only quantities' courses for the first bogie are given below. It is through the front bogie that the vehicle receives the initial impulse to change the ride direction. This fact causes the courses of the monitored quantities to have a less favourable character for the front bogie.

\section{Evaluation of the monitored quantities' courses}

The chapter presents the results of a series of simulation analyses, the individual variants being marked as follows:

Variant 1: the bogies are oriented according to Fig. 4 a), the pivot pin is firmly attached to the car body

Variant 2: the bogies are oriented according to Fig. 4 a), the pivot pin is rotatably mounted on the car body

Variant 3: the chassis are oriented according to Fig. 4b), the pivot pin is firmly attached to the car body

Variant 4: the bogies are oriented according to Fig. 4 (b), the pivot pin is rotatably mounted on the car body

The ride of the vehicle significantly describes the value of the lateral displacement of the wheelset from the track axis, which for the analysed variants is shown in Fig. 6. It can be deduced from its course that in all cases the front bogie of the vehicle passes through an arc in a close to the chord position. From the point of view of the work of the wheel profile, the basic requirement for its correct function is therefore met. Variants 3 and 4 show a similar lateral deflection on both wheelsets, while variant 4 looks more perspective in view of entering the arc. When riding on a straight track, the undulatory movement of wheelsets occurs, with the smallest amplitude of this movement being achieved in variant 1 .
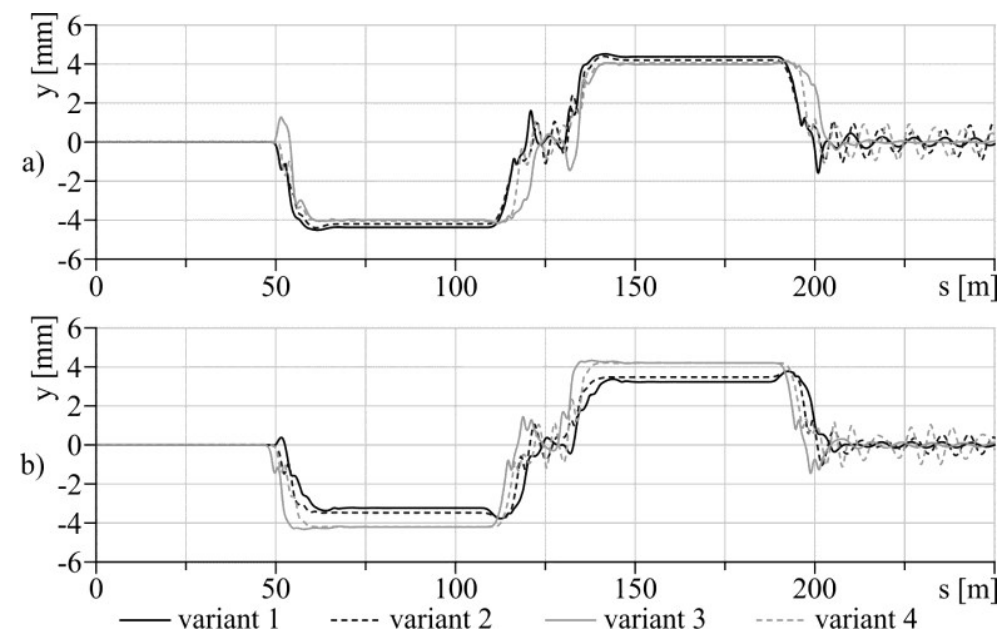

Fig. 6. Lateral displacement of the wheelset towards the track axis

a) the first wheelsets, b) the second wheelset

The rail vehicle is not only carried but also guided by its track. It is therefore necessary to know the course of the guiding forces in the wheel-rail contacts. In a favorable case, the 
guiding forces should act in the same direction on both wheelsets of the bogie. If their size is similar, one of the assumptions for uniform wear of the two wheelsets is created. In case of a ride in a track arc, the increase in the guiding forces should not be sudden. From Fig. 7 it can be deduced that these requirements seem to best fit the variants 3 and 4 . However, it is not sufficient for the process of guiding forces to be analysed separately. It is also necessary to evaluate them in terms of safety against derailment, i.e. to analyse the course of the ratio of the guiding and vertical wheel force as shown in Fig. 8. On the basis of the calculated data, it can be concluded that all proposed solutions are safe against derailment, with variants 3 and 4 appearing more perspective, as more favorable values are achieved on the attacking wheelset.

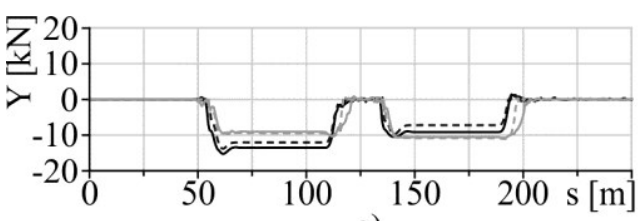

a)

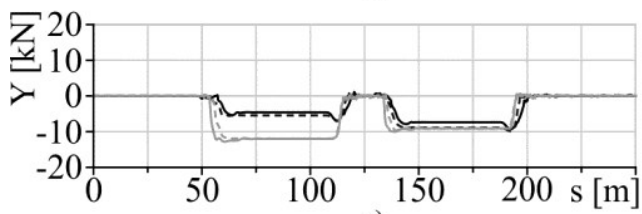

c)

— variant $1 \quad$---- variant 2

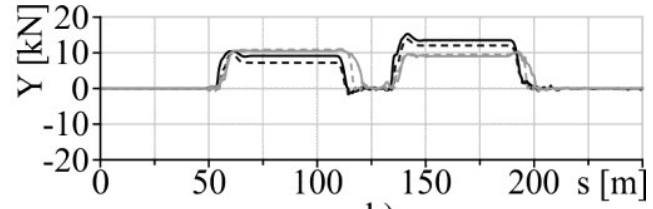

b)

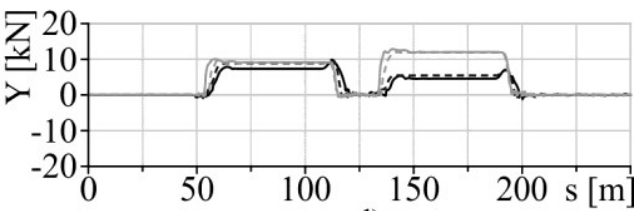

d)

Fig. 7. Lateral forces in contact:

a) front left wheel- rail, b) front right wheel - rail,

c) rear left wheel - rail, d) rear right wheel - rail

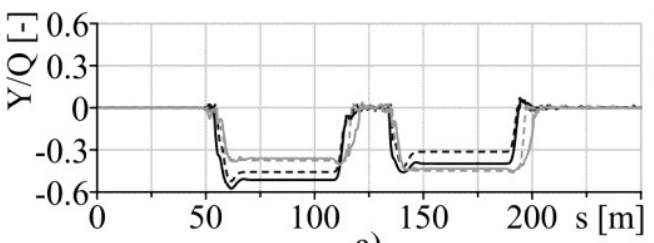

a)

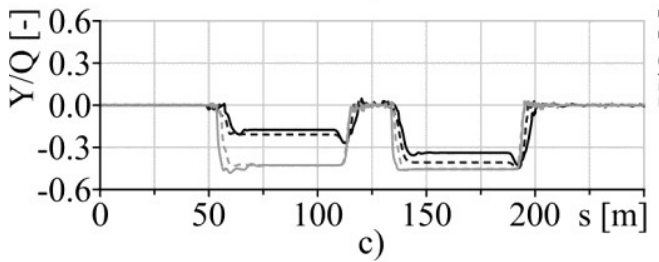

— variant $1 \quad$-.-- variant 2

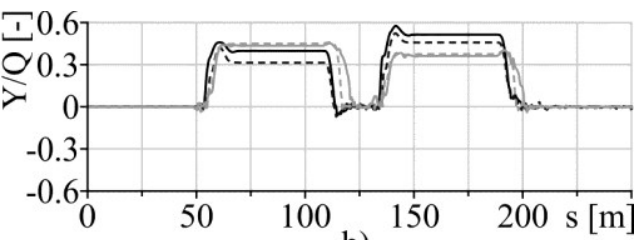

b)

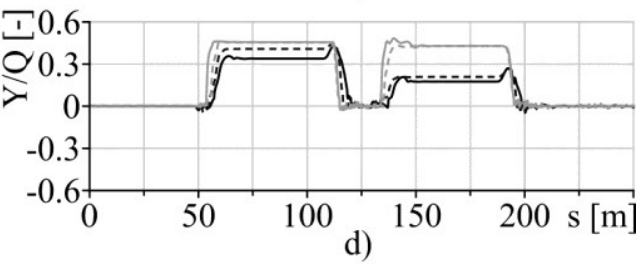

variant 3

variant 4

Fig. 8. Safety against derailment index:

a) front left wheel - rail, b) front right wheel - rail,

c) rear left wheel - rail, d) rear right wheel - rail

A significant indicator of the reliability of the bogie is the value of angles of attack, for the analysed variants shown in Fig. 9. In a favorable case, it should be close to zero, in reality it usually reaches values of up to $3^{\circ}$. In an event that non-zero angles of attack are present, the wheel-rail contact is overloaded by the transfer of more signifficant lateral forces, which often can not be transfered through the adhesive bond, significant creep 
occurs in the lateral and longitudinal directions. When two-point contact is achieved, the contact surfaces are often overloaded by forces circulating between the contact points of the wheel tread and the wheel flange. The resulting product of such operation is increased noise and wear of the contact pair. From Fig. 9 it can be read that although the analysed track has an arc with the smallest possible radius allowed by the standard [15] to be used, particularly small angles of attack are achieved. From this point of view, options 1 and 2 appear in perspective.
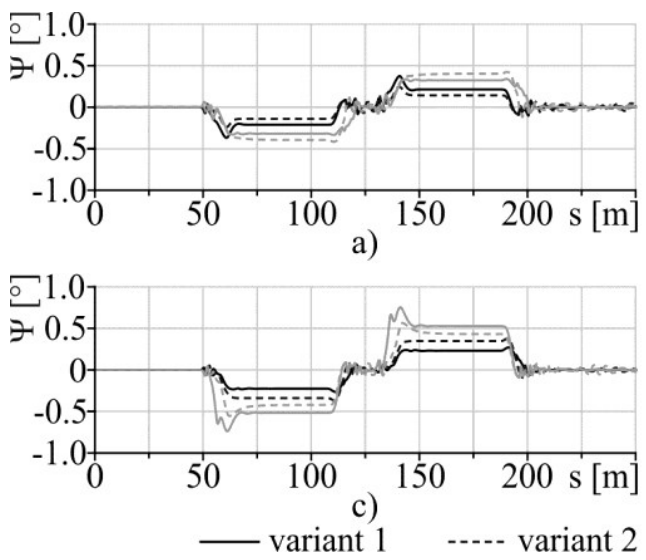
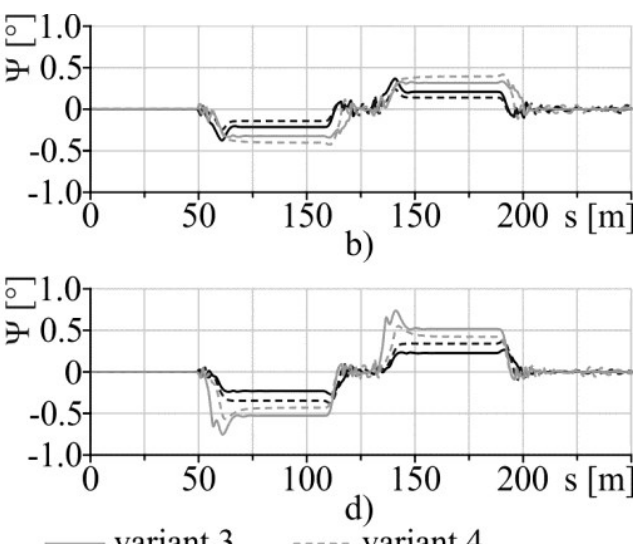

Fig. 9. Angles of attack:

a) front left wheel - rail, b) front right wheel - rail,

c) rear left wheel - rail, d) rear right wheel - rail

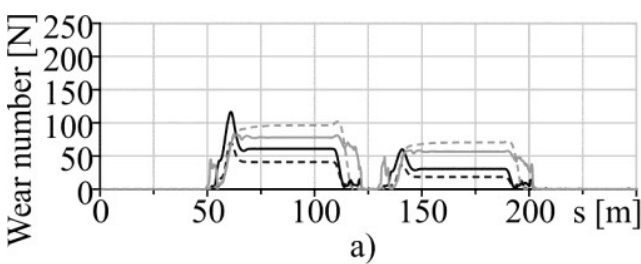

a)

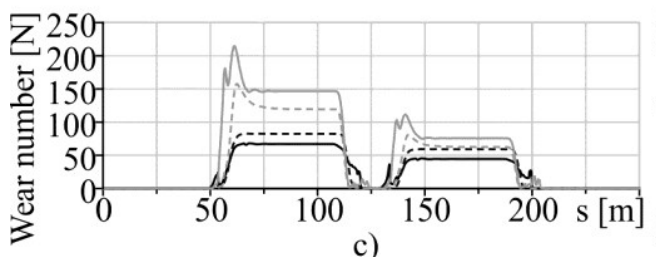

— variant $1 \quad$----- variant 2

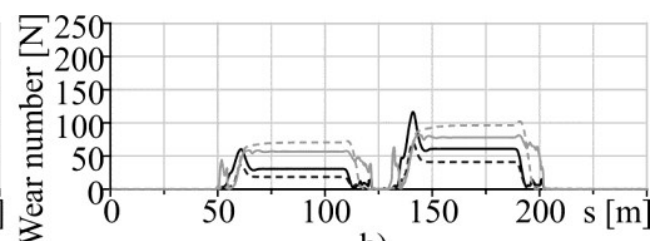

b)

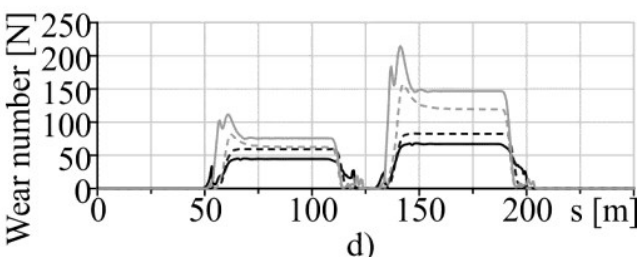

variant 3

variant 4

Fig. 10. Wear number in contact:

a) front left wheel - rail, b) front right wheel - rail,

c) rear left wheel - rail, d) rear right wheel - rail

Fig. 10 shows the course of the wear numbers, i.e. intensity of interaction in individual wheel-rail contacts. It can be concluded that a significant improvement is achieved in all analyzed cases compared to vehicles with no steering mechanism. From among the proposed possibilities of placing and mounting of the bogie, variant 2 seems perspective, as there are no significant amplitudes in its course and overall it reaches low values. 


\section{Conclusion}

The article, by means of a simulation analysis of a rail vehicle, compares in total four variants of car body to bogie junction design differing in the way the bogie is placed and mounted. It provides a view of the problem in terms of the signal courses of deflection of the two wheelsets from the track axis, the course of the guiding forces, the safety against derailment index, the angle of attack and the wear number. Based on the results obtained, the authors consider among the analysed proposals for the given track as most perspective the second variant, i.e. the orientation of the bogies such that the wheelset with a single axle box is headed towards the stem and a pivot pit mounted by means of a pair of rotary bonds, one of which is in the junction of the car and the central element and the second in junction between the central element and the gear frame.

Further improvement in ride parameters is likely to be achieved if the junction of the car with the bogie is not located at the center of the bogie wheelbase. The authors'collective is currently engaged in optimizing the pivot pin shift value and determination of the corresponding changes in vehicle behavior.

The work was supported by the Cultural and Educational Grant Agency of the Ministry of Education of the Slovak Republic in project No. KEGA 077ŽU-4/2017: Modernization of the Vehicles and engines study program. The work was also supported by the project No. APVV-0842-11: Equivalent railway operation load simulator on the roller rig and VEGA Nr. 1/0927/15: Research of the use of alternative fuels and hybrid drives on traction vehicles with aim to reduce fuel consumption and air pollutants production.

Research-Educational Center of Rail Vehicles (VVCKV)

\section{References}

1. J. Dižo, Analysis of a goods wagon running on a railway test track. Manufacturing technology: journal for science, research and production 16 (4), 667-672

2. J. J. Kalker, Three-dimensional elastic bodies in rolling contact. 314 p. ISBN: 0-79230712-7 (1990)

3. L. Smetanka, P. Št’astniak, J. Dižo, Comparison of wear laws programmed in SIMPACK. Experimental and computational methods in engineering. ISBN 978-807414-698-5 (2017)

4. J. Gerlici, T. Lack, V. Hauser, M. Maňurová, O. S. Nozhenko, K. O. Kravchenko, Carriage bogie. Utility model no. UA 114040 U, category: B61F5/30. Kyjiv: Ukrajinskyj instytut promyslovoji vlasnosti (UKRPATENT), 9 p. (2017)

5. M. Loulová, V. Hauser, J. Gerlici, T. Lack, O. S. Nozhenko, O. P. Kravchenko, K. O. Kravchenko, Carriage bogie. Utility model application no. u201703246, category: B61F5/30. Kyjiv: Ukrajinskyj instytut promyslovoji vlasnosti (UKRPATENT), 9 p. (2017)

6. M. D. Ivanov, A. A. Ponomarev, B. K. M. Ieropol'skij, Tramways T-3. 240 p. (1977)

7. V. Hauser, O. Nozhenko, K. Kravchenko, M. Loulová, J. Gerlici, T. Lack, Impact of three axle boxes bogie to the tram behavior when passing curved track. Procedia Engineering. 192, 295-300 (2017)

8. A. Chudzikiewicz, B. Sowinski, Modelling and simulation of trams bogies with fully independently rotating wheels. In Dynamics of vehicles on roads and tracks. 14271434. ISBN: 978-1-4987-7702-5 (2016)

9. A. Chudzikiewicz, Simulation of rail vehicle dynamics in MATLAB environment. In Vehicle system dynamics 33 (2), 107-119, ISSN 0042-3114 (2000) 
10. R. Melnik, S. Koziak, Rail vehicle suspension condition monitoring - approach and implementation. Journal vibroengineering, Lithuania, ISSN 1392-8716

11. A. Sapietová, M. Sága, P. Novák, R. Bednár, J. Dižo, Design and application of multisoftware platform for solving of mechanical multi-body system problems. Mechatronics: Recent technological and scientific advances, 345-354 (2011)

12. M. Blatnický, M. Štauderová, J. Dižo, Numerical analysis of the structure girder for vehicle axle scale calibration. Procedia Engineering 177, 510-515 (2017)

13. J. Dižo, J. Harušinec, M. Blatnický, Multibody system of a rail vehicle bogie with a flexible body. Manufacturing technology 15 (5), 781-788

14. J. Dižo, M. Blatnický, B. Skočilasová, Computational modelling of the rail vehicle multibody system including flexible bodies. Communications: scientific letters of the University of Žilina 17 (3), 31-36 (2015)

15. TNŽ 736361 Geometrical position and layout of railways with $1000 \mathrm{~mm}$ gauge. (ŽSR, Bratislava, 37 p., 2007) 